Originally published as:

Pauly, D., Kirchner, S., Stoermann, B., Schreiber, T., Kaulfuss, S., Schade, R., Zbinden, R., Avondet, M.-A., Dorner, M.B., Dorner, B.G.

Simultaneous quantification of five bacterial and plant toxins from complex matrices using a multiplexed fluorescent magnetic suspension assay

(2009) Analyst, 134 (10), pp. 2028-2039.

DOI: $10.1039 / B 911525 K$

The definitive version is available at: http://pubs.rsc.org/en/Content/ArticleLanding/2009/AN/b911525k 


\title{
Simultaneous quantification of five bacterial and plant toxins from complex matrices using a multiplexed fluorescent magnetic suspension assay†
}

\author{
Diana Pauly, ${ }^{1}$ Sebastian Kirchner, ${ }^{1}$ Britta Stoermann, ${ }^{1}$ Tanja Schreiber, ${ }^{1}$ Stefan Kaulfuss, ${ }^{1}$ Rüdiger \\ Schade, ${ }^{2}$ Reto Zbinden, ${ }^{3}$ Marc-André Avondet, ${ }^{3}$ Martin B. Dorner, ${ }^{1}$ and Brigitte G. Dorner ${ }^{* 1}$ \\ ${ }^{1}$ Center for Biological Safety, Microbial Toxins (ZBS3), Robert Koch-Institut, Nordufer 20, 13353 \\ Berlin, Germany. E-mail: DornerB@rki.de \\ ${ }^{2}$ Institute of Pharmacology CCM/CBF, Charité-Universitätsmedizin Berlin, Dorotheenstrasse 94 , \\ 10117 Berlin, Germany \\ ${ }^{3}$ LABOR SPIEZ, 3700 Spiez, Switzerland \\ † Electronic supplementary information (ESI) available: comparison of multiplex toxin detection \\ techniques, exemplary immunisation schema for rabbit and mouse, and titer development of rabbit.
}

\begin{abstract}
Proteotoxins such as ricin, abrin, botulinum neurotoxins type $A$ and $B$ (BoNT/A, BoNT/B) and staphylococcal enterotoxin B (SEB) are regarded as potential biological warfare agents which could be used for bioterrorism attacks on the food chain. In this study we used a novel immunisation strategy to generate high-affinity monoclonal and polyclonal antibodies against native ricin, BoNT/A, and BoNT/B. The antibodies were used along with antibodies against SEB and abrin to establish a highly sensitive magnetic and fluorescent multiplex bead array with excellent sensitivities between $2 \mathrm{ng} / \mathrm{L}$ and 546 $\mathrm{ng} / \mathrm{L}$ from a minimal sample volume of $50 \mathrm{~mL}$. The assay was validated using 20 different related analytes and the assay precision was determined. Advancing the existing bead array technology, the novel magnetic and fluorescent microbeads proved amenable to enrichment procedures, by further increasing sensitivity to $0.3-85 \mathrm{ng} / \mathrm{L}$, starting from a sample volume of $500 \mathrm{~mL}$. Furthermore, the method was successfully applied for the simultaneous identification of the target toxins spiked into complex food matrices like milk, baby food and yoghurt. On the basis of our results, the assay appears to be a good tool for large-scale screening of samples from the food supply chain.
\end{abstract}

\section{Introduction}

Ever since the alleged preparation of ricin by terrorist groups and the ricin findings in the US postal system in 2003, it has become evident that there is an urgent need to develop rapid, sensitive and specific detection systems for toxins. High molecular-weight proteotoxins such as ricin, abrin, botulinum neurotoxins (BoNT) and staphylococcal enterotoxin B (SEB) are regarded as potential biological warfare agents. They could be used for small-scale attacks on the basis of their availability, ease of preparation, their high toxicity and/or the lack of medical countermeasures. One likely scenario focuses on toxins as water or food contaminants, especially in food that is not further heated before consumption.1,2

Ricin and abrin are highly toxic plant lectins, derived from the seeds of the ornamental plants Ricinus communis and Abrus precatorius, respectively. Both lectins are prototypic A-B toxins which effectively inhibit protein synthesis by depurinating the $28 \mathrm{~S}$ ribosomal RNA. For ricin, the oral toxicity in humans expressed as half-maximal lethal dose (LD50) is estimated to be $1-20 \mathrm{mg} / \mathrm{kg}$ body weight and for abrin $0.1-1 \mathrm{mg} / \mathrm{kg}$ body weight.3,4 Both R. communis and A. precatorius seeds contain a second toxic lectin named $R$. communis agglutinin and $A$. precatorius agglutinin, which are highly homologous (around $90 \%$ sequence identity for ricin and R. communis agglutinin) to ricin or abrin, respectively, but are less toxic.5-7

The rod-shaped bacterium Clostridium botulinum produces seven different serotypes of BoNT. Serotypes BoNT/A, BoNT/B, BoNT/E and BoNT/F have been shown to cause botulism in humans. Botulinumneurotoxins act at the neuromuscular junction 
of cholinergic neurons to induce flaccid paralysis by interfering with components of the vesicle fusion machinery. Exceedingly small quantities of toxin are sufficient for poisoning: the oral lethal dose of botulinum toxin for man is approximately $1 \mathrm{mg} / \mathrm{kg} .8$ Staphylococcal enterotoxin B (SEB) is one of several heatstable enterotoxins produced by the Gram-positive bacterium Staphylococcus aureus, which is known as a major human pathogen. The toxin functions both as potent gastrointestinal toxin, as well as a superantigen that stimulates non-specific T-cell proliferation and cytokine release. On the basis of its functional activity SEB has been classified as an incapacitating agent by the Centers of Disease Control and Prevention (Atlanta, GA, USA). The minimum level of toxin causing gastroenteritis in humans is approximately $1 \mathrm{ng} / \mathrm{g}$ of food. 1,9

From a diagnostic point of view, toxins are a challenging group of agents as they may act in the absence of the producing organism and its genetic information. Therefore, their detection cannot - as in the case of viruses and bacteria - rely on nucleic acid-based methods. Rather, the toxin itself has to be detected either by immunological, mass spectrometric or functional assays.10-12 Immunological techniques offer the advantages of being highly specific, selective and sensitive, and furthermore can be implemented into field-deployable devices. For the sensitive immunological detection of toxins, specific antibodies are required which bind their target protein with high affinity. The generation of high-affinity antibodies specific for native toxins is difficult, however, since in most cases animals cannot be immunised with the active molecules, e.g. the toxic dose of botulinum toxins is lower than the immunogenic dose. Inactivation of native toxins under at least partial maintenance of 3dimensional (3-D) epitopes is necessary in order to prevent the poisoning of animals and to simultaneously enable generation of antibodies against native 3-D structures. To this end, different approaches have been described, for example, immunisation using immunogenic peptides derived from the toxins, immunisation with recombinant sub-chains or fragments of toxins, immunisation with toxoid (formaldehyde-treated or heat-inactivated toxin) or with DNA.13-15 These methods are both time-consuming and, to a variable degree, labour-intensive. Hence, in this study we have tested a novel immunisation strategy for ricin, BoNT/A and BoNT/B: we covalently immobilised the native toxins onto microbeads in order to reduce their toxicity in vivo.

Most laboratory tests for the afore-mentioned toxins are performed in a single test format using sandwich enzyme linked immunosorbent assay (ELISA) techniques.14,16-20 It is often desirable, however, to monitor multiple toxins simultaneously in order to reduce materials used, as well as cost and effort.21 Different techniques for multiplex toxin detection have been reported in recent years, and some of them have already been included into field-deployable devices (see Supplementary Table $\mathrm{S} 1 \dagger$ ). Most of the multiple analyte assays or biosensors suffer from a lack of sensitivity, as they detect ricin, SEB or BoNT in the mid mg/L-range. Very few multiplex devices have been shown to deliver sensitive results from complex food matrices.22-24 Among the multiplex platforms described, the suspension array technology, also called Luminex xMAP technology (Luminex Corp., Austin, USA), is of interest for the broad-range use in standard laboratories, as it is commercially available. The conventional suspension array technology uses polystyrene microspheres which are embedded with precise ratios of red and infrared fluorescent dyes, thus yielding an array of 100 bead sets which are spectrally unique and can be distinguished by flow cytometry. The assay principle is similar to a sandwich ELISA: differently coloured microbeads are covalently coupled to antibodies specific for different antigens, thus allowing the simultaneous detection of multiple antigens from a minimal sample volume of $50 \mathrm{~mL}$. The bound analytes are detected via biotinylated secondary antibodies and the fluorescent reporter streptavidin-phycoerythrin. The Luminex flow cytometer addresses (i) the fluorescent signature of the bead set and (ii) the intensity of the reporter signal per bead set.

With respect to detection of biothreat agents, the conventional suspension array technology has been described for the detection of certain relevant agents.25-29 In this report, we describe the application of newly available fluorescent microbeads, which are also magnetic. The spectrally unique, magnetic beads have a diameter of $6.5 \mathrm{mmand}$ a surface area of $133 \mu \mathrm{m} 2$ and, similar to the conventional polystyrene beads, 100 different bead sets are available. Magnetic beads offer the major advantage of being easily separated from complex food matrices and are thus amenable to immunomagnetic enrichment procedures.

In the current work, we applied a novel immunisation strategy to develop monoclonal antibodies (mAb) and polyclonal antibodies (pAb) specific for native ricin, BoNT/A, BoNT/B in different experimental animals. The antibodies were used along with antibodies specific for SEB and abrin to develop a 5plex fluorescent magnetic suspension array with sensitivities in the low $\mathrm{ng} / \mathrm{L}$-range from a minimal sample volume of $50 \mathrm{~mL}$. Enrichment of toxins from a larger sample volume $(500 \mathrm{~mL})$ was possible and resulted in even increased sensitivities for all five toxins. Finally, 
we show that the multiplex assay can be used to simultaneously detect ricin, BoNT/A, BoNT/B, abrin and SEB from complex food matrices such as beverages, baby food and yoghurt.

\section{Experimental}

\section{Toxins and bacterial strains}

Ricin (purity 98\%, kindly provided by U. Pfüller, University Witten/Herdecke, Germany) was purified along with R. communis agglutinin from the seeds of R. communis, according to standard procedures.30 Purified ricin A- and ricin B-chains, different lectins (Helix pomatia agglutinin, Dolichos biflors agglutinin) and SEB were obtained from Sigma-Aldrich (Munich, Germany).

Both the purified $150 \mathrm{kDa}$ neurotoxins and the neurotoxin protein complexes of botulinum toxin $A$ (BoNT/A, derived from Hall strain), botulinum toxin $B$ (BoNT/B, from Okra strain), botulinum toxin $E$ (BoNT/E, from Alaska strain) and botulinum toxin $F$ (BoNT/F, from Langeland strain) were obtained from Metabiologics (Madison, WI, USA). Abrin and staphylococcal enterotoxins were from Toxin Technology (Sarasota, FL, USA) and Sigma-Aldrich (Munich, Germany). For validation of the multiplex suspension array we used bacterial cell culture supernatants from the following strains: $C$. botulinum strain 2298 (serotype A, 62A), strain 2267 (serotypeA, CECT551), strain 1029 (serotype B,NCTC7273), strain 2625 (serotype E, CB-S21E), strain 2297 (serotype F, 83-4304), all kindly provided by F.Gessler (Göttingen, Germany). Appropriate safety measures were followed when handling toxins. Personal protective equipment was worn and toxins were handled under a class II vertical laminar flow cabinet (Heraeus Herasafe, Thermo Fisher Scientific, Waltham,MA,USA). Prior to disposal, toxin-containing solutions were treated with $5 \%$ sodium hydroxide. SEB-containing samples as well as consumables were autoclaved at $121^{\circ} \mathrm{C}$ for $60 \mathrm{~min}$.

\section{Inactivation of toxins for immunisation}

For immunisations using immobilised native toxins, ricin, BoNT/A, and BoNT/B were covalently coupled to tosyl-activated Dynabeads M-280 (size $2.8 \mathrm{~mm}$; Invitrogen, Karlsruhe, Germany) using a modified coupling procedure. Briefly, $6.5 \times 10^{8}$ Dynabeads were washed twice with buffer $A(0.1 \mathrm{M}$ sodium-phosphate buffer, $\mathrm{pH} 7.4$ ), resuspended in $100 \mathrm{~mL}$ toxin solution (concentration: $0.5 \mathrm{~g} / \mathrm{L}$ for ricin and $0.05-0.2 \mathrm{~g} / \mathrm{L}$ for BoNT/A or BoNT/B, in phosphate-buffered saline (PBS)) and were incubated for $20 \mathrm{~h}$ at $37^{\circ} \mathrm{C}$, under rotation. The toxin-beadsolution was washed twice with $800 \mathrm{~mL}$ buffer C (PBS containing $0.1 \%$ mouse serum, $0.1 \%$ rabbit serum or $0.1 \%$ ovalbumin, depending on the species to be immunised: mouse, rabbit or chicken) and reactive binding sites were blocked with $800 \mathrm{~mL}$ buffer $\mathrm{D}$ ( $0.2 \mathrm{M}$ Tris containing $0.1 \%$ mouse serum, $0.1 \%$ rabbit serum or $0.1 \%$ ovalbumin, $\mathrm{pH} 8.5$, respectively) for $4 \mathrm{~h}$ at $37^{\circ} \mathrm{C}$, under rotation. The toxin-beads were washed at least three times with $800 \mathrm{~mL}$ buffer $\mathrm{C}$ until no free toxin was detectable in the supernatant via ELISA and stored in $500 \mathrm{~mL}$ buffer $\mathrm{C}$ at $4{ }^{\circ} \mathrm{C}$. We have observed that, after prolonged storage at $4{ }^{\circ} \mathrm{C}(>15 \mathrm{months})$, free toxin becomes detectable in the supernatant. Therefore, we routinely use toxin-coupled beads for about 6 months.

In order to generate monoclonal ( $\mathrm{mAb}$ ) and polyclonal antibodies ( $\mathrm{pAb})$, we used covalently immobilised ricin, BoNT/A and BoNT/B to immunise mice, chickens and/or rabbits. For each toxin and each species separately, we tested the amount of immobilised toxin inducing a specific titer (exemplarily shown for rabbit RB77 in Supplementary Table S2 and Fig. S1†).

As an alternative and conventional approach, toxins were inactivated using formaldehyde using standard procedures. 31

Briefly, BoNT/A and BoNT/B toxoids were prepared by adding $37 \%$ formaldehyde to the purified neurotoxin, resulting in a final concentration of $0.5 \%$ formaldehyde. This solution was kept for 21 days at $37^{\circ} \mathrm{C}$ under rotation. 


\section{Generation of monoclonal antibodies}

$\mathrm{BALB} / \mathrm{c}$ mice were bred under pathogen-free conditions at the Federal Institute for Risk Assessment (Berlin, Germany) and were used at the age of 8 weeks. In the case of ricin, three mice were immunised intraperitoneally (i.p.) with $5 \mathrm{~mL}$ ricin-beads, corresponding to $2.5 \mathrm{mg}$ native ricin covalently coupled to the beads (this is approximately a 15-fold LD50 in mice) in complete Freund's adjuvant (CFA, Sigma-Aldrich, Munich, Germany). Mice were boosted several times with increasing doses of the same antigen (up to $10 \mathrm{~mL}$ of ricin-beads, corresponding to $5 \mathrm{mg}$ native ricin and a 30-fold LD50 coupled to beads) i.p. in incomplete Freund's adjuvants (IFA, Sigma-Aldrich, Munich, Germany) at four-week intervals. Subsequently, mice were boostered several times with up to $16 \mathrm{mg}$ of free native ricin. Three days before fusion, 4-16 $\mathrm{mg}$ of native ricin were applied i.p. once per day (see Supplementary Table S3†). In the case of BoNT/A and BoNT/B immunisation of mice, $25 \mathrm{mg}$ toxoid in CFA were applied for primary immunisation followed by up to 4 boosts using $50 \mathrm{mg}$ toxoid in IFA. Once the mice showed a BoNT-specific titer, they were boosted with a 50 -fold LD50 of native BoNT in IFA. On day $-3,-2$, and -1 before fusion, mice were injected i.p. with a 250-fold LD50 of native BoNT in PBS. In the case of SEB, which is less toxic than the above-mentioned toxins, BALB/c mice were immunised three times with 25-50 mg recombinant SEB (Toxin Technology, Sarasota, FL, USA) and boostered on day $-3,-2$ and -1 before fusion as above.

Hybridomas were produced by fusing spleen cells from immunised mice with myeloma cells (P3-X63Ag8.653, American Type Culture Collection) at a ratio of $2: 1$ in polyethylene glycol 1500 (PEG, Roche Diagnostics, Mannheim, Germany) according to standard procedures.32 Cells were plated on BALB/c thymocytes as feeder cells in RPMI 1640 media containing $20 \%$ foetal calf serum, $50 \mathrm{mM} 2-$ mercaptoethanol, $50 \mathrm{U} / \mathrm{mL}$ recombinant murine IL-6, $1 \%$ glutamine, $5.8 \mathrm{mM}$ azaserine and $100 \mathrm{mM}$ hypoxanthine. Supernatants from all fusions were screened for specific antibodies using an indirect ELISA against the corresponding toxins on days 10-14, post-fusion. In a parallel approach, we also screened for functionally blocking ricin antibodies, similarly to Furukawa-Stoffer et al.33 In this case, fused cells were plated in RPMI 1640 media containing the supplements indicated above and $16 \mathrm{ng} / \mathrm{L}$ native ricin. Hybridomas surviving the ricin exposure were tested for neutralising capacity in a cytotoxicity assay. All positive hybridoma clones were subcloned at least once and stable subclones were tested for intracellular IgG production by flow cytometry.34 Immunoglobulins (IgG) were purified from hybridoma supernatants by means of HiTrap protein G-Sepharose column (GE Healthcare Life Science, Piscatawa, NJ, USA) and checked for purity using sodium dodecyl sulfate-polyacrylamide gel electrophoresis (SDS-PAGE). The concentration of purified antibodies was measured using the Bradford-Assay (Bio-Rad Laboratories, Munich, Germany). The isotype of monoclonal antibodies was determined using the IsoStrip mouse monoclonal antibody isotyping kit (Roche Applied Science, Mannheim, Germany).

\section{Production of polyclonal antibodies}

In order to generate rabbit polyclonal antibodies $(\mathrm{pAb})$, rabbits were immunised first with beadimmobilised BoNT/A and later on with free native BoNT/A using the following protocol: (i) several immunisations with $100 \mathrm{~mL}$ BoNT/A-beads (corresponding to $5 \mathrm{mg}$ native BoNT/A coupled to beads; this is equivalent to a 500 000-fold LD50 in mice) subcutaneously (s.c.), either in CFA or later IFA; (ii) after detection of a specific titer, animals were further boosted s.c. with increasing doses of free native BoNT/A (up to $160 \mathrm{ng}$ ) in IFA. In the case of BoNT/B, immunisations were done similarly, except for the doses used for immunisations: (i) several immunisations with up to $30 \mathrm{~mL}$ BoNT/B-beads (corresponding to $15 \mathrm{mg}$ native BoNT/B coupled to beads; this is equivalent to the 3000000 -fold LD50 in mice) in CFA or IFA, respectively; (ii) up to $20 \mathrm{ng}$ free native BoNT/B in IFA (see Supplementary Table S2 and Fig. S1†). Blood samples were collected 10-15 days after each immunisation and tested for specific antibodies using indirect ELISA against the corresponding toxins. IgG were purified from rabbit serum by means of protein G-Sepharose column as described above.

For the generation of polyclonal chicken antibodies, animals were immunised by the following protocol: in the case of ricin, chickens were first immunised intramuscularly (i.m.) with $12 \mathrm{~mL}$ ricin-beads (corresponding to $6 \mathrm{mg}$ native ricin coupled to beads) followed by several immunisations with up to 20 $\mathrm{mg}$ free native ricin in IFA. For of BoNT/A and BoNT/B, immunisation started with $20 \mathrm{~mL}$ BoNT/Abeads (corresponding to $1 \mathrm{mg}$ native BoNT/A immobilised on beads) or $200 \mathrm{~mL}$ BoNT/B-beads (corresponding to $10 \mathrm{mg}$ native BoNT/B coupled to beads) in CFA, respectively, and was increased up to $30 \mathrm{mg}$ immobilised BoNT in IFA given i.m. Eggs were collected from days 10 to 20 post- 
immunisation and polyclonal IgY were prepared from the egg yolk using fractionated PEG precipitation as described elsewhere.35

\section{Ricin cytotoxicity assay and test for functional blockade in vitro}

A cytotoxicity assay was used for determining the neutralising capacity of ricin-specific hybridoma supernatants and purified mAb, as described previously. 36 Briefly, Vero cells $\left(1 \times 10^{5}\right.$ cells per $\mathrm{mL}$, $100 \mathrm{~mL}$ per well, American Type Culture Collection) were seeded in 96-well plates and incubated for $18 \mathrm{~h}$ at $37^{\circ} \mathrm{C}$. On the next day, the cells were treated for $2 \mathrm{~h}$ either with ricin alone (final concentration of ricin $10 \mathrm{mg} / \mathrm{L}$ ) or with a mixture of ricin and antibodies which have been pre-incubated separately for $1.5 \mathrm{~h}$ at $37^{\circ} \mathrm{C}$ (final concentration of antibodies $75 \mathrm{mg} / \mathrm{L}$ to $0.6 \mathrm{mg} / \mathrm{L}$ ). After washing, the treated cells were further incubated at $37^{\circ} \mathrm{C}$ for $20 \mathrm{~h}$. The viability of the Vero cells was quantified using the CellTiter96 Non-Radioactive Cell Proliferation Assay (Promega, Madison, WI, USA).

In order to compare the toxicity of free native ricin with ricin covalently immobilised on Dynabeads, we used a similar assay where serial dilutions of the free or immobilised toxin were tested in parallel. To quantify the amount of ricin immobilised on the beads we subtracted the amount of toxin that could be detected via sandwich ELISA in all washing solutions of the coupling reaction from the amount of toxin which has been initially used as input in the coupling reaction (coupling efficiency about $50 \%$ ).

\section{Indirect ELISA}

MaxiSorp microtiter plates (Nunc, Wiesbaden, Germany) were coated with antigen $(500 \mathrm{mg} / \mathrm{L}, 50 \mathrm{~mL}$ per well) in PBS overnight at $4{ }^{\circ} \mathrm{C}$ and blocked with blocking buffer (PBS, $0.1 \%$ Tween $20,2 \%$ skimmed milk (Merck, Darmstadt, Germany)) for $1 \mathrm{~h}$. After washing, the antibody was added $(10 \mathrm{mg} / \mathrm{L}$ in blocking buffer) for $1 \mathrm{~h}$ and was detected using horseradish peroxidase (HRP)-labelled goat antimouse IgG, donkey antichicken IgG or goat anti-rabbit IgG, as appropriate (Dianova, Hamburg, Germany) and 3,30,5,50-tetramethylbenzidine (TMB; Sigma-Aldrich, Munich, Germany).

\section{Sandwich ELISA}

MaxiSorp microtiter plates were coated with $\mathrm{mAb}(10 \mathrm{mg} / \mathrm{L})$ in $50 \mathrm{~mL}$ PBS overnight at $4{ }^{\circ} \mathrm{C}$ and blocked with casein buffer (Diavita, Heidelberg, Germany) for $1 \mathrm{~h}$ at room temperature. Following washing, $50 \mathrm{~mL}$ of toxin was added in serial dilutions from $100 \mathrm{mg} / \mathrm{L}$ to $0.05 \mathrm{ng} / \mathrm{L}$ in assay buffer (PBS, $0.1 \%$ bovine serum albumin (BSA; Sigma-Aldrich, Munich, Germany)) and incubated for $2 \mathrm{~h}$ at room temperature. The sandwich ELISA was developed by incubation with biotin-labelled secondary antibody diluted in casein buffer (1 $\mathrm{h}$, room temperature), followed by washing and detection with streptavidin-PolyHRP40 (0.5 mg/L, Diavita, Heidelberg, Germany) and TMB.

\section{Immunoblot}

Antigens were separated by $12 \%$ SDS-PAGE under reducing or non-reducing conditions and transferred onto PVDF-membrane (Invitrogen, Karlsruhe, Germany), using standard techniques. Briefly, the membrane was blocked with blocking buffer (PBS, 0.1\% Tween 20, $2 \%$ skimmed milk) overnight at $4{ }^{\circ} \mathrm{C}$ and was then incubated with appropriately diluted primary antibody in blocking buffer for $1 \mathrm{~h}$. After washing, the membrane was probed with biotinylated goat anti-mouse IgG, donkey antichicken IgG or goat anti-rabbit IgG (Dianova, Hamburg, Germany), as appropriate, in blocking buffer for $30 \mathrm{~min}$ and was developed using alkaline phosphatase and CDP-Star (Perkin Elmer, Waltham, MA, USA).

\section{Coupling of antibodies or streptavidin-phycoerythrin to fluorescent magnetic microspheres}

Six different sets of spectrally-unique, carboxylated magnetic $6.5 \mathrm{~mm}$-microspheres were provided by Luminex Corp. (Austin, USA) for coupling of antibodies specific to ricin, abrin, SEB, BoNT/A, BoNT/B or the fluorescence quenching control streptavidin- phycoerythrin (SA-PE; Prozyme, San Leandro, CA, USA). Covalent coupling of the capture antibodies or SA-PE, alternatively, to the microspheres was performed according to manufacturer's instructions (Bio-Plex Amine Coupling Kit, Bio-Rad 
Laboratories, Munich, Germany). Antibody sets of capture and biotinylated detection antibodies which gave optimal results for multiplex toxin detection are given in Table 1.

\section{Multiplex toxin detection}

All assays were carried out in a 96-well flat bottom microtiter plate (VWR International, Darmstadt, Germany) at room temperature, protected from light and shaken at $600 \mathrm{rpm}$. The multiplex assay was performed as follows: for each toxin to be analysed, 5000 antibody-labelled magnetic fluorescent microspheres, corresponding to selected bead regions (Table 1), were washed twice with PBS-T (PBS, $0.05 \%$ Tween 20 ) and were added to $50 \mathrm{~mL}$ of sample containing the indicated concentrations of toxins in either PBS-B (PBS, 1\% BSA) or diverse food extracts, as specified in the text. The toxinmicrosphere-mixture was incubated for $2 \mathrm{~h}$ under shaking. Alternatively, for the enrichment experiments the bead-toxin-mixtures were incubated in a larger sample volume $(500 \mathrm{~mL})$ for $16 \mathrm{~h}$, under rotation. After incubation the microspheres were transferred into a smaller assay volume of 50 $\mathrm{mL}$ using a Dynal MPC-S magnet (Invitrogen, Karlsruhe, Germany). For automated washing and separation of the magnetic beads from the samples, a 96-well format magnet washer was used (hydroFLEX, Tecan, Crailsheim, Germany). The beads were washed twice with PBS-T and a cocktail of titrated biotinylated detection antibodies was added $(100 \mathrm{~mL} /$ well, $1 \mathrm{~h})$. The beads were washed as before and incubated with $4 \mathrm{mg} / \mathrm{L} \mathrm{SA}-\mathrm{PE}(100 \mathrm{~mL} /$ well) for $30 \mathrm{~min}$. Following washing, the beads were resuspended in $125 \mathrm{~mL}$ PBS-B and the fluorescent signature of the beads and the corresponding PE-reporter signal was recorded using a Luminex system, in combination with the Bio-Plex Manager software (high calibration setting; Bio-Rad Laboratories, Munich, Germany). Routinely, 100 beads per region were measured in the 100 bead map with the DD-gates at 8000 and 22000.

\section{Validation of the magnetic fluorescent bead array}

For statistical analysis, the limit of detection (LOD) was calculated by adding three standard deviations to the mean of the mean fluorescence intensities (MFI) of six blanks.

Specificity was determined by measuring cross-reactivity to a number of related antigens at a fixed concentration in the upper plateau of the standard curves. At this concentration of the crossreactive antigen (Ccross), the apparent concentration of the analyte (Canalyte) was calculated from the measured MFI-value of the cross-reactive antigen, using the standard curve of the analyte. Reactivity $(R)$ was expressed in percent of the apparent analyte concentration divided by the concentration of the crossreactive antigen:37

$$
R=100 \times\left[C_{\text {analyte }} / C_{\text {cross }}\right]
$$

To assess within- (intra) and between- (inter) run precision, we measured the standard curves for the 5 -plex assay at least 6 times over 3 days, with 2 replicates per concentration. The coefficient of variation (CV) equals the standard deviation divided by the mean for 6 values of a given concentration.

\section{Analysis of complex food samples}

Liquid or semisolid food samples (milk, iced coffee, carrot juice, baby food, yoghurt) were homogenised with an equal volume of gelatine-phosphate buffer $(0.2 \%$ gelatine in $28 \mathrm{mM} \mathrm{Na} 2 \mathrm{HPO} 4$, $\mathrm{pH}$ 6.2) using a BagMixer (Interscience, Saint Nom la Bretèche, France). After $1 \mathrm{~h}$ incubation under vigorous shaking the extracts were centrifuged, the supernatant was adjusted to $\mathrm{pH} 7.0$ and $50 \mathrm{~mL}$ of the homogenate was spiked with the EC50 concentrations of ricin, abrin, SEB, BoNT/A, and BoNT/B derived from the multiplex toxin standard curves (see Fig. 1 and Table 1; EC50 is defined as the half-maximum concentration that can be measured by the 5-plex suspension array for each analyte). Five thousand magnetic fluorescent microspheres labelled with the different capture antibodies and corresponding to the five different bead sets were added and the 5-plex assay was performed as described above. As fluorescence quenching control, 5000 microspheres coupled to SA-PE were incubated in an independent reaction for $2 \mathrm{~h}$ with the sample matrix or buffer as described above. After washing, the PE-reporter signal was determined in the Luminex system. For each of the five toxins spiked into food, the recovery rate of the observed amount 
of toxin compared to the expected known amount of toxin in the sample was expressed as a percentage. In the case of the fluorescence quenching control, the signal obtained in the complex food matrix was compared to the signal obtained in buffer and expressed as a percentage.

\section{Results and discussion}

\section{Generation of antibodies against native toxins: a novel immunisation approach}

In order to circumvent the problem of high toxicity of proteotoxins in vivo we established a novel immunisation strategy for ricin, BoNT/A and BoNT/B. We covalently immobilised the native toxins onto $2.8 \mathrm{~mm}$-microbeads, in order to reduce toxicity. Exemplarily for ricin, we compared the toxicity of immobilised ricin versus free native ricin using a cell-culture cytotoxicity assay (Fig. 2A). Vero cells were treated with ricin or immobilised ricin at different concentrations and the concentration whereby $50 \%$ of the cells survived after $24 \mathrm{~h}$ was determined (IC50). The immobilisation of ricin onto beads reduced its toxicity approximately 116 -fold, from an IC50 of $0.6 \mathrm{mg} / \mathrm{L}$ (ricin) to $70 \mathrm{mg} / \mathrm{L}$ (ricin-beads). A significant eduction

of toxicity was also seen for immobilised ricin in a mouse lethality test (data not shown). The toxin still showed residual toxicity, however, requiring careful titration prior to immunisation. Nevertheless, covalent coupling of the native toxin to microbeads enabled us to apply much higher antigen doses for immunisation than would have been possible for the free native toxin.

The exact mechanism by which the reduction in toxicity is achieved is unknown. Covalent binding of ricin to the bead surface could occur via the A-chain, B-chain, or both, since the coupling process is not a directed process. We assume that the normal uptake of ricin into target cells via binding to sugar residues, and subsequent endocytosis (which is initiated via the B-chain), is substantially reduced for the immobilised toxin. It has been shown, however, that professional antigen-presenting cells, such as macrophages and dendritic cells, are able to phagocytose $3 \mathrm{~mm}$-beads and are able to efficiently present bead-bound

proteins to T- and B-cells, thus initiating a specific immune response. 38 Particulate antigens have been found to be presented 1000 -fold more efficiently on MHC class I and class II compared to soluble antigens.39-41 For different target molecules such as DNA, peptides, proteins and toxins, a variety of carriers have been successfully used for immunisation and vaccine development, e.g. gold or iron particles, nitrocellulose, virus-like particles, polystyrene or latex beads and biocompatible particles.4245

Possible explanations for the residual toxicity of the immobilised ricin may be the following: if the covalent attachment to the bead surface occurred via the B-chain, the toxic A-chain could detach from the B-chain intracellularly and exert its functional activity. Furthermore, part of the native holo-toxin could stick on the bead surface via non-covalent binding forces and could detach upon application to cells in vitro or upon injection in vivo.

\section{Characterisation of toxin-specific antibodies}

In order to generate monoclonal ( $\mathrm{mAb}$ ) and polyclonal antibodies ( $\mathrm{pAb}$ ), we used covalently immobilised ricin, BoNT/A and BoNT/B to immunise mice, chickens and/or rabbits. The immobilised toxins were used either for the first immunisations followed by booster immunisations using free native toxins, or were used throughout the complete immunisation regimen (see Experimental section). For each toxin and each species separately, we tested the amount of immobilised toxin inducing a specific titer. This point is exemplarily demonstrated for one species and toxin in the Supplementary Data† (Table S2 and

Fig. S1). It is worth mentioning that for the toxins and species analysed, we did not observe an increase in titer after switching from immobilised toxin to free native toxin (data not shown).

In the case of ricin, the novel immunisation approach yielded 7 hybridoma clones and chicken IgY, which specifically recognised native ricin with high affinity. Table 2 summarises the characterisation of all $\mathrm{mAb}$ and $\mathrm{pAb}$. Hybridoma clones R18 and R109 recognising the ricin A-chain or ricin B-chain, respectively, gave superior results in sandwich ELISA. Both hybridoma clones R18 and R109 specifically reacted with ricin and the highly homologous $R$. communis agglutinin. They did not react with the closely-related plant toxin abrin, or with BoNT, SEB or BSA in an indirect ELISA (Fig. 2B and 
data not shown). In the case of BoNT/A and BoNT/B, the strategy of using immobilised BoNT/A and BoNT/B for immunisation yielded pAb of high quality in chickens and rabbits (Table 2). This approach did not work well, however, in mice as no significant titer emerged (data not shown). This might be due to a lower immunogenicity of BoNT in comparison to ricin. Therefore, we used the classical toxoidimmunisation strategy in mice, with the extension that mice were boosted with the 50- to 250-fold half-maximal lethal dose (LD50) of native toxins, as soon as a toxoid-specific titer was detectable. Using this immunisation protocol, we obtained (among others) hybridoma A1688 specific for BoNT/A and hybridoma B755 specific for BoNT/B (Table 2). Both of these hybridomas exclusively reacted with their cognate antigen, but not with related BoNT serotypes, BSA (Fig. 2C), ricin, abrin or SEB (data not shown). Clones A1688 and B755 gave superior results in sandwich ELISA assays and were therefore used for further experiments. In the case of SEB, which is less toxic than the above-mentioned toxins, high quality $\mathrm{mAb}$ were produced after immunising with recombinant SEB. Among 70 positive hybridoma, clones S419 and S1001 were selected on the basis of their strong and selective recognition of SEB for further experiments (Fig. 2D).

\section{Multiplex toxin detection using a magnetic fluorescent suspension array}

As the main focus of the current work we implemented our antibodies against ricin (clones R109, R18), BoNT/A (clone A1688), BoNT/B (clone B755) and SEB (clones S419, S1001), along with commercially available reagents against abrin, into a magnetic and fluorescent suspension array suitable for the detection and quantification of the toxins from food. To this end, we used novel magnetic, spectrally-unique microspheres $(6.5 \mathrm{~mm}$ diameter). First, we determined the optimal antibody pairs for single-toxin detection using titrations of the individual toxins in buffered solution. An antibody pair was considered optimal if it specifically detected its cognate antigen with high sensitivity, without cross-reacting with any other toxin. These optimal antibody pairs were combined for multiplextoxin detection (Table 1). The result of the multiplex optimisation process is presented in Fig. 1 and Table 3. Using the fluorescent magnetic suspension array for the analysis of a five-toxin-mixture in a sample volume of $50 \mathrm{~mL}$, we obtained an LOD of $2 \mathrm{ng} / \mathrm{L}$ for ricin and $3 \mathrm{ng} / \mathrm{L}$ for SEB. In the case of BoNT/A and BoNT/B, a minimal amount of $21 \mathrm{ng} / \mathrm{L}$ and $73 \mathrm{ng} / \mathrm{L}$, respectively, was detected. For abrin, the LOD was determined at $546 \mathrm{ng} / \mathrm{L}$, (Fig. 1 and Table 3). For all five antigens investigated, the dynamic range of the assay spanned about three orders of magnitude of concentration above the LOD (Fig. 1).

The antibody performance of the 5-plex magnetic fluorescent suspension array was compared with an amplified plate-bound single-toxin ELISA using the same antibody pairs as in the multiplex assay (ELISA: use of biotinylated secondary antibodies plus streptavidin-PolyHRP40; suspension array: detection using streptavidin-PE). For the four toxins, where we used our in-house reagents (ricin, SEB, BoNT/A, BoNT/B), we obtained similar standard curves and detection limits using the conventional single-toxin plate-bound ELISA and the 5-plex suspension array (Fig. 1 and Table 3). However, in the case of abrin, the plate-bound ELISA showed a lower detection limit, possibly due to more optimal reaction conditions and/or due to the amplification system used.

One major advantage of the novel Luminex microbeads is that they can be used for immunomagnetic enrichment procedures.

We investigated the 5-plex magnetic fluorescent bead array for enrichment of the toxins from a 500 $\mathrm{mL}$ sample volume. Whilst the sample volume was increased 10 -fold, the number of beads and the toxin concentrations were kept constant, compared to the standard $50 \mathrm{~mL}$-reaction. In order to obtain ultimate sensitivity, the bead-toxin-mixtures were rotated for $16 \mathrm{~h}$ instead of $2 \mathrm{~h}$. Under these conditions the maximal sensitivity was reached with an LOD of $0.3 \mathrm{ng} / \mathrm{L}$ for SEB, $4 \mathrm{ng} / \mathrm{L}$ for ricin, 6 $\mathrm{ng} / \mathrm{L}$ for BoNT/A, $24 \mathrm{ng} / \mathrm{L}$ for BoNT/B, and $85 \mathrm{ng} / \mathrm{L}$ for abrin (Table 3). For SEB, BoNT/A, BoNT/B and abrin the enrichment procedure resulted in a 3- to 10-fold improvement in sensitivity, while the ricin assay already gave maximal sensitivity using the standard protocol. Further increase of sample volume from 500 to $5000 \mathrm{~mL}$, or an increase in incubation time (>16 h) did not significantly change the LOD for any of the five toxins analysed (data not shown).

To our knowledge, there is no other multiplex detection system described which is able to detect five bacterial and plant toxins simultaneously from a minimal sample volume of $50-500 \mathrm{~mL}$, in the low $\mathrm{ng} / \mathrm{L}-$ range (compare Supplementary Table S1†). As an example several toxins, namely ricin, BoNT/A, BoNT/B and/or SEB, can be simultaneously detected using the NRL Array Biosensor,23,46 the bidiffractive grating iosensor (BDG),47 the fiber optic fluorometer RAPTOR22 or the QTL biosensor.22 These systems offer the advantage of being portable, but are less sensitive with LODs in 
the low to medium $\mathrm{mg} / \mathrm{L}$-range. Their lower sensitivity is compensated for by a more rapid assay time (15 minutes compared to 3.5 hours for the magnetic fluorescent suspension array). While the different biosensors are optimised for assay time and portability, the focus of our work was to establish and validate a lab-based platform for highly sensitive detection of multiple toxins.

It should be noted that some of the above-mentioned antibody- based detection systems detect BoNT toxoids instead of native toxins.23,25,48 In our experience, antibodies which recognise the toxoids do not usually bind the native toxins with high affinity. The development of antibodies which detect native toxins with high affinity is challenging, but necessary to obtain ultimate sensitivity.

In order to improve sensitivity, Anderson and Taitt recently used the tyramide signal amplification strategy to detect toxins using the conventional (non-magnetic) Luminex technology: depending on the antigen analysed they were able to increase the sensitivity approximately 3- to 8-fold in a multiplex approach.25 For several toxins, however, the tyramide signal amplification failed or gave even weaker results (LODs for ricin $1 \mathrm{mg} / \mathrm{L}$ and for BoNT/A toxoid $10 \mathrm{mg} / \mathrm{L}$ ). 25 We also tested several amplification systems in order to further increase sensitivity (UltraAmp Multi- Assay Signal Amplifier, Genisphere, Hatfield, PA USA; Rolling circle amplification technology, Qiagen, Hamburg, Germany). However, using amplification systems in the current 5-plex magnetic fluorescent bead array resulted in a higher background fluorescence, without any beneficial effect on sensitivity (data not shown).

Due to the principle of the Luminex XMAP technology, an increase in the number of microspheres used together with increased sample volume was not beneficial. The XMAP technology measures the mean MFI signal per bead set and an increase in the number of beads per sample lowers the total amount of analyte bound per bead. Conversely, a beneficial effect by lowering the number of beads and thereby increasing the amount of analyte per bead is limited by statistical considerations, as a suitable high number of beads must be analysed for a precise measurement.49

\section{Validation of the magnetic fluorescent suspension array}

As all five toxins are measured simultaneously, the specificity for each analyte is imperative. The specificity of the 5-plex magnetic fluorescent bead array was determined using 20 different antigens: different plant and animal lectins, closely-related staphylococcal toxins, different human pathogenic BoNT serotypes - either purified toxins or toxin complexes - and $\mathrm{C}$. botulinum culture supernatants. In order to determine crossreactivity for all antigens a high concentration close to, or in the upper plateau of, the toxin's standard curves was chosen (Table 4). All of the five toxins in our 5-plex assay were specifically detected with virtually no cross-reactivity to the other antigens. Ricin-beads detected ricin and weaker R. communis agglutinin which show about $90 \%$ sequence identity at the amino acid level. Among the staphylococcal enterotoxins SEC1 has the highest homology to SEB (67\% on amino acid level) and is weakly detected by the SEB-beads (Table 4).

The variability of the 5-plex assay was determined at three concentrations in buffered solution (standard $50 \mathrm{~mL}$-reaction, $2 \mathrm{~h}$ incubation). For each of the toxins analysed, the mean withinrun precision was $5-10 \%$ (Table 5 ) and was therefore similar to within-run precisions reported for commercially available cytokine multiplex xMAP-assays, using conventional, non-magnetic beads.50 The mean inter-assay precision values for all analytes (except ricin) were between 14 and $23 \%$ (Table 5). For ricin, we obtained a mean precision of $52 \%$. Similarly, inter-assay precision values for different cytokines in commercial multiplex cytokine xMAPassays were reported to be optimally $<25 \%$, but single analytes showed higher between-assay values $(>45 \%) \cdot 50,51$

For the multiplex detection systems cited above, no information is available on their specificity and variability.22,23,47,52

\section{Analysis of complex food matrices}

BoNT/A, /B, /E and SEB have been isolated in food poisoning cases and ricin has been associated with accidental ingestions of castor beans in humans.53 With respect to potential bioterrorism attacks, one likely scenario focuses on toxins as water or food contaminants, especially food that is not heated before consumption. Pilot experiments showed that compared to nonmagnetic beads, magnetic beads offer the advantage of being easily separated from complex food matrices and the washing process 
can be automated. We therefore tested our 5-plex assay for the detection of the five toxins spiked into milk, iced coffee,

carrot juice, baby food and yoghurt. For each toxin, the indicated food was spiked with the EC50

concentration of the five toxins (Table 1) and recovery rates were determined. As shown in Fig. 3, the recovery rate of the observed amount of toxin compared to the expected known amount of toxin was between 50 and $100 \%$. Baby food as a matrix gave poorer recovery rates of approximately $25 \%$ for BoNT/A and BoNT/B (Fig. 3). On the other hand, detection of ricin in carrot juice resulted in elevated recovery rates, approximately $150 \%$ (Fig. 3 ). Obviously, matrix effects appear to play a major role in assay performance, and this has also been observed by other groups.11,54,55 An obvious explanation might be that food components mask or even expose antibody-binding epitopes, thereby decreasing or increasing the analyte's detection. Additionally, food components can also nonspecifically bind to an antibody, leading to elevated signals.

Aside from matrix interference with antibody binding, apparently low recovery rates could be explained by the quenching of the reporter signal's fluorescence by food components. Indeed, when we incubated in a separate reaction the food matrix or buffer with beads covalently coupled to SA-PE, we were able to estimate the fluorescence quenching effect due to the matrix components. Baby food as the matrix significantly quenched the SA-PE signal to $75 \%$, indicating that the low recovery rate is mainly due to a fluorescence quenching effect (Fig. 3F).

A major goal of this study was to assess the detection efficiency of the magnetic and fluorescent bead array for the simultaneous detection of toxins from food. If we take into account the human LD50 for ricin, abrin, BoNT/A and BoNT/B and the ED50 of SEB, we conclude that the assay is sufficiently sensitive to detect the afore-mentioned toxins far below the LD50 or ED50, respectively (Table 3). The LD50/ED50 values in Table 3 rely on estimated oral doses for humans56-60 calculated for a $10 \mathrm{~kg}$ toddler and a $100 \mathrm{~mL}$ serving of food. For all five toxins, there is at least a 2-3 orders of magnitude difference between the LOD in a $50 \mathrm{~mL}$ sample volume and the estimated oral LD50/ED50. It is important to note that even for the lower recovery rates obtained in the case of BoNT/A and BoNT/B in baby food, our assay sensitivity is sufficient to detect the five toxins below the lethal or effective doses (the spiked concentrations are already below the oral lethal doses, e.g. the spiked concentration EC50[BoNT/A] $1 / 4700 \mathrm{ng} / \mathrm{L}$, is approximately 140 -fold less than the lethal dose for a $10 \mathrm{~kg}$ toddler and $100 \mathrm{~mL}$ serving).

\section{Conclusions}

One major issue in the field of immunological detection of toxins is that high quality antibodies cannot be easily induced in experimental animals, since the native molecules are highly toxic for the animals. While it is relatively easy to produce antibodies against inactivated toxins, it is a challenge to generate antibodies which recognise the native molecules with high affinity. To our knowledge, this is the first study which describes the use of beadimmobilised native toxins for the immunisation of different species. The preparation of the antigen is rapid $(<24 \mathrm{~h})$ and high quality monoclonal and polyclonal antibodies can be obtained without expression of recombinant toxin sub-chains, chemical inactivation procedures or cloning of DNA expression vectors. The strategy might be useful for other highly toxic substances, provided that their immunogenicity in the selected laboratory animal is high enough.

Using our antibodies along with commercially available reagents, we developed a magnetic and fluorescent bead array capable of simultaneously detecting five microbial and plant toxins not only in buffer, but also within complex food matrices. While a variety of biosensor technologies work well in the laboratory using buffered solutions, many technologies fail when targets are tested in complex matrices, most probably due to interference of matrix components with binding reagents or technical equipment. Using the magnetic and fluorescent bead array, we were able to detect ricin, abrin, BoNT/A, BoNT/B and SEB in the low ng/L-range from a minimal sample volume of $50-500 \mathrm{~mL}$, which is superior to LODs obtained by other multiplex detection systems. The use of the novel magnetic and fluorescently-coded beads appears to be a major improvement of the conventional Luminex XMAP technology for three main reasons: First, enrichment procedures are now possible which result in a further improvement of sensitivity. Second, colloidal or particulate samples can now be analysed since the beadimmobilised target molecule can be easily separated from the matrix. And third, the washing process in a 96-well format can be automated, thus reducing the variability of the assay. 
As an open platform, the magnetic XMAP technology is ready for the implementation of up to 100 userspecific antibody pairs. Since the magnetic and fluorescent antibody array is compatible with analysis of complex food matrices, it might be a useful tool for large-scale screening of the food supply chain. A further improvement in technology will be the introduction of a mobile device, allowing the step from a benchtop application to a field-deployable device.

\section{Acknowledgements}

Work presented in this manuscript was supported by grants of the German Federal Ministry of Health, the Federal Institute for Drugs and Medical Devices and the Federal Ministry of Defence to B. G. D. We thank C. Zimmermann (Bio-Rad Laboratories, Munich, Germany) for helpful support and J. Rybarczyk, J. Millert and B. Diemar for excellent technical assistance. We also thank our colleagues from the Department of Imaging Techniques for photos of C. botulinum, S. aureus, R. communis and A. precatorius. We are grateful to G. Pauli and B. Brembs for discussions and critical reviews.

\section{References}

1 Medical aspects of biological warfare, ed. Z. F. Dembek, Department of Defense, Office of The Surgeon General, US Army, Borden Institute, Washington, DC, 2007.

2 J. Sobel, A. S. Khan and D. L. Swerdlow, Lancet, 2002, 359, 874-880.

3 S.M. Bradberry, K. J. Dickers, P. Rice, G. D. Griffiths and J. A. Vale, Toxicol. Rev., 2003, 22, 65-70. 4 K. J. Dickers, S. M. Bradberry, P. Rice, G. D. Griffiths and J. A. Vale, Toxicol. Rev., 2003, 22, 137142.

5 A. Bagaria, K. Surendranath, U. A. Ramagopal, S. Ramakumar and A. A. Karande, J. Biol. Chem., 2006, 281, 34465-34474.

6 G. Funatsu, M. R. Islam, Y. Minami, K. Sung-Sil and M. Kimura, Biochimie, 1991, 73, 1157-1161.

7 J. Zhan and P. Zhou, Toxicology, 2003, 186, 119-123.

8 S. S. Arnon, R. Schechter, T. V. Inglesby, D. A. Henderson, J. G. Bartlett, M. S. Ascher, E. Eitzen, A. D. Fine, J. Hauer, M. Layton, S. Lillibridge, M. T. Osterholm, T. O’Toole, G. Parker, T. M. Perl, P. K.

Russell, D. L. Swerdlow and K. Tonat, J. Am. Med. Assoc., 2001, 285, 1059-1070.

9 N. Balaban and A. Rasooly, Int. J. Food Microbiol., 2000, 61, 1-10.

10 A. H. Peruski and L. F. Peruski Jr., Clin. Diagn. Lab. Immunol., 2003, 10, 506-513.

11 M. Lindström and H. Korkeala, Clin. Microbiol. Rev., 2006, 19, 298-314.

12 F. Becher, E. Duriez, H. Volland, J. C. Tabet and E. Ezan, Anal. Chem., 2007, 79, 659-665.

13 M. Zeng, Q. Xu, M. Elias, M. E. Pichichero, L. L. Simpson and L. A. Smith, Vaccine, 2007, 25, 7540-7548.

14 C. Shone, P. Wilton-Smith, N. Appleton, P. Hambleton, N. Modi, S. Gatley and J. Melling, Appl. Environ. Microbiol., 1985, 50, 63-67.

15 D. D. Pless, E. R. Torres, E. K. Reinke and S. Bavari, Infect. Immun., 2001, 69, 570-574.

16 O. Attrée, V. Guglielmo-Viret, V. Gros and P. Thullier, J. Immunol. Methods, 2007, 325, 78-87.

17 V. Guglielmo-Viret and P. Thullier, J. Immunol. Methods, 2007, 328, 70-78.

18 G. J. Doellgast, M. X. Triscott, G. A. Beard, J. D. Bottoms, T. Cheng, B. H. Roh, M. G. Roman, P. A. Hall and J. E. Brown, J. Clin. Microbiol., 1993, 31, 2402-2409.

19 J. Guo, B. Shen, Y. Sun, M. Yu and M. Hu, Hybridoma, 2006, 25, 225-229.

20 A. H. Peruski, L. H. Johnson III and L. F. Peruski Jr., J. Immunol. Methods, 2002, 263, 35-41.

21 M. Seidel and R. Niessner, Anal. Bioanal. Chem., 2008, 391, 1521-1544.

22 J. J. Gooding, Anal. Chim. Acta, 2006, 559, 137-151.

23 F. S. Ligler, K. E. Sapsford, J. P. Golden, L. C. Shriver-Lake, C. R. Taitt, M. A. Dyer, S. Barone and C. J. Myatt, Anal. Sci., 2007, 23, 5-10.

24 R. Ganapathy, S. Padmanabhan, Y. P. Eric, S. Moochhala, L. K. Lionel and G. Ponnampalam, Front. Biosci., 2008, 13, 5432-5440.

25 G. P. Anderson and C. R. Taitt, Biosens. Bioelectron., 2008, 24, 324-328.

26 B. J. Hindson, M. T. McBride, A. J. Makarewicz, B. D. Henderer, U. S. Setlur, S. M. Smith, D. M. Gutierrez, T. R. Metz, S. L. Nasarabadi, K. S. Venkateswaran, S. W. Farrow, B. W. Colston Jr. and J. M. Dzenitis, Anal. Chem., 2005, 77, 284-289.

27 M. T. McBride, S. Gammon, M. Pitesky, T. W. O'Brien, T. Smith, J. Aldrich, R. G. Langlois, B. Colston and K. S. Venkateswaran, Anal. Chem., 2003, 75, 1924-1930. 
28 J. Wang, Y. Yang, L. Zhou, J. Wang, Y. Jiang, K. Hu, X. Sun, Y. Hou, Z. Zhu, Z. Guo, Y. Ding and R. Yang, Immunopharmacol. Immunotoxicol., 2009, DOI: 10.1080/08923970902740837, Epub ahead of print.

29 L. Wang, K. D. Cole, A. K. Gaigalas and Y. Z. Zhang, Bioconjugate Chem., 2005, 16, 194-199.

30 T. T. Lin and S. L. Li, Eur. J. Biochem., 1980, 105, 453-459.

31 G. A. Hottle and A. Abrams, J. Immunol., 1947, 55, 183-187.

32 E. Harlow, D. Lane and E. Harlow, Using Antibodies: A laboratory manual, Cold Spring Harbor Laboratory Press, New York, 1988.

33 T. L. Furukawa-Stoffer, D. C. Mah, J. W. Cherwonogrodzky and R. J. Weselake, Hybridoma, 1999, $18,505-511$.

34 B. G. Dorner, S. Steinbach, M. B. Hüser, R. A. Kroczek and A. Scheffold, J. Immunol. Methods, 2003, 274, 83-91.

35 D. Pauly, M. Dorner, X. Zhang, A. Hlinak, B. Dorner and R. Schade, Poult. Sci., 2009, 88, 281-290.

36 C. R. McGuinness and N. J. Mantis, Infect. Immun., 2006, 74, 3463-3470.

37 U. Wollenberger, R. Renneberger, F. F. Bier and F. W. Scheller, Antikörper in der Analytischen Biochemie, Wiley-VCH, Weinheim, 1st edn, 2003.

38 Z. Shen, G. Reznikoff, G. Dranoff and K. L. Rock, J. Immunol., 1997, 158, 2723-2730.

39 C. V. Harding and R. Song, J. Immunol., 1994, 153, 4925-4933.

40 M. Kovacsovics-Bankowski, K. Clark, B. Benacerraf and K. L. Rock, Proc. Natl. Acad. Sci. U. S. A., 1993, 90, 4942-4946.

41 L. Vidard, M. Kovacsovics-Bankowski, S. K. Kraeft, L. B. Chen, B. Benacerraf and K. L. Rock, J. Immunol., 1996, 156, 2809-2818.

42 M. Singh, A. Chakrapani and D. O'Hagan, Expert Rev. Vaccines, 2007, 6, 797-808.

43 S. Raychaudhuri and K. L. Rock, Nat. Biotechnol., 1998, 16, 1025-1031.

44 I. Cenci Di Bello, B. Poulain, C. C. Shone, L. Tauc and J. O. Dolly, Eur. J. Biochem., 1994, 219, 161-169.

45 K. A. Knudsen, Anal. Biochem., 1985, 147, 285-288.

46 F. S. Ligler, C. R. Taitt, L. C. Shriver-Lake, K. E. Sapsford, Y. Shubin and J. P. Golden, Anal.

Bioanal. Chem., 2003, 377, 469-477.

47 T. O'Brien, L. H. Johnson III, J. L. Aldrich, S. G. Allen, L. T. Liang, A. L. Plummer, S. J. Krak and A. A. Boiarski, Biosens. Bioelectron., 2000, 14, 815-828.

48 Y. Kwon, C. A. Hara, M. G. Knize, M. H. Hwang, K. S. Venkateswaran, E. K. Wheeler, P. M. Bell, R. F. Renzi, J. A. Fruetel and C. G. Bailey, Anal. Chem., 2008, 80, 8416-8423.

49 D. A. Vignali, J. Immunol. Methods, 2000, 243, 243-255.

50 K. Kofoed, U. V. Schneider, T. Scheel, O. Andersen and J. Eugen-Olsen, Clin. Chem., 2006, 52, 1284-1293.

51 J. F. Djoba Siawaya, T. Roberts, C. Babb, G. Black, H. J. Golakai, K. Stanley, N. B. Bapela, E.

Hoal, S. Parida, P. van Helden and G. Walzl, PLoS One, 2008, 3, e2535.

52 G. P. Anderson, K. D. King, K. L. Gaffney and L. H. Johnson, Biosens. Bioelectron., 2000, 14, $771-$ 777.

53 T. Garland and E. M. Bailey, Rev. sci. tech. Off. int. Epiz., 2006, 25, 341-351.

54 E. A. Garber, R. M. Eppley, M. E. Stack, M. A. McLaughlin and D. L. Park, J. Food Prot., 2005, 68, 1294-1301.

55 S. K. Sharma, J. L. Ferreira, B. S. Eblen and R. C. Whiting, Appl. Environ. Microbiol., 2006, 72, 1231-1238.

56 S. Budavari, M. J. O'Neil, A. Smith, P. E. Heckelman and J. F. Kinneary, The Merck Index: An Encyclopedia of Chemicals, Drugs, and Biologicals, Merck \& Co., Inc., Whitehouse Station, NJ, USA, 1996.

57 D. R. Franz, in Textbook of military medicine: medical aspects of chemical and biological warfare, specialty editors F. R. Sidell, E. T. Takafuji and D. R. Franz, Borden Institute, TMM Publications, Washington, DC, USA, 1997, pp. 603-619.

58 E. J. Schantz and E. A. Johnson, Microbiol. Rev., 1992, 56, 80-99.

59 M. S. Bergdoll and A. C. L. Wong, in Foodborne Infections and Intoxifications, ed. H. P. Riemann and D. O. Cliver, Elsevier, Amsterdam, London, Burlington, San Diego, 2006, pp. 523-562.

60 B. A. Herrero, A. E. Ecklung, C. S. Streett, D. F. Ford and J. K. King, Exp. Mol. Pathol., 1967, 6, $84-95$. 


\section{Tables and Figures}

Table 1 Optimal antibody sets used for multiplexed fluorescent magnetic suspension array

\begin{tabular}{|c|c|c|c|c|c|c|c|}
\hline Antigen & Bead set & Capture antibody & Source & $\begin{array}{l}\text { Amount of capture antibody } \\
\text { per } 1.25 \times 10^{6} \text { microspheres }\end{array}$ & Detection antibody & Source & $\mathrm{EC}_{50}[\mathrm{ng} / \mathrm{L}]^{\mathrm{f}}$ \\
\hline Ricin & 25 & mAb R 109 & In-house (Table 2) & $15 \mu \mathrm{g}$ & mAb R18 & In-house (Table 2) & 2500 \\
\hline Abrin & 8 & mAb TC- $7026-001$ & Tetracore, Rockville, MD, USA & $45 \mu \mathrm{g}$ & pAb TC-7027-001 & Tetracore, Rockville, MD, USA & 40000 \\
\hline SEB & 26 & mAb S419 & In-house (Table 2) & $15 \mu \mathrm{g}$ & mAb S1001 & In-house (Table 2) & 500 \\
\hline BoNT/A & 36 & mAb A1688 & In-house (Table 2) & $15 \mu \mathrm{g}$ & Horse anti-BoNT/A,/B,$/ \mathrm{E}$ & $\begin{array}{l}\text { Novartis Behring, Marburg, } \\
\text { Germany }\end{array}$ & 700 \\
\hline BoNT/B & 7 & $\mathrm{mAb}$ B755 & In-house (Table 2) & $15 \mu \mathrm{g}$ & Horse anti-BoNT/A,/B,$/ \mathrm{E}$ & $\begin{array}{l}\text { Novartis Behring, Marburg, } \\
\text { Germany }\end{array}$ & 7000 \\
\hline SA-PE & 82 & - & Prozyme, San Leandro, CA, USA & $0.9 \mu \mathrm{g}$ & - & - & - \\
\hline
\end{tabular}

a EC50 is defined as the half-maximum concentration that can be measured by the 5-plex suspension array for each analyte (see later in Fig. 1). This concentration was used for spiking complex food matrices and recovery experiments (see later in Fig. 3).

Table 2 Characterisation of anti-toxin antibodiesa

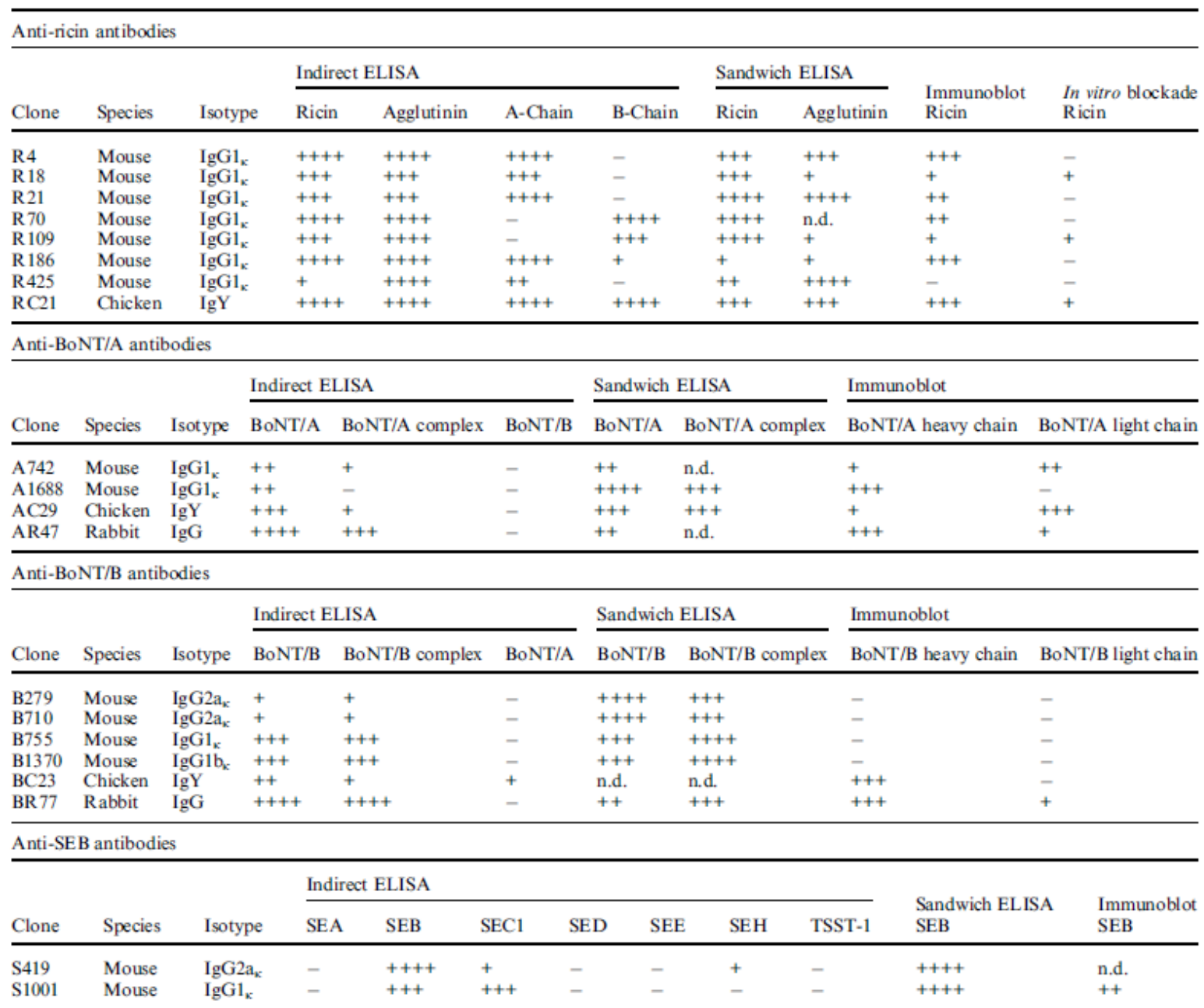


a The signal strengths of the different antibodies in the indicated immunological assays are compared to the respective antibody yielding the highest signal in the technique used for a given toxin. The signal intensities are indicated on a relative scale: $(-)$ corresponds to no signal; $(+)$ corresponds to $<25 \%$ relative signal intensity; $(++)$ corresponds to $25-50 \%$ relative signal intensity; $(+++)$ corresponds to $50-75 \%$ relative signal intensity and $(++++)$ corresponds to $>75 \%$ relative signal intensity. For in vitro blockade a yes (+)/no (-) response is indicated. n.d. $1 / 4$ not determined.

Table 3 Comparison of detection limits (LOD)

\begin{tabular}{|c|c|c|c|c|c|}
\hline \multirow[b]{2}{*}{ Toxin } & \multirow[b]{2}{*}{ ELISA [ng/L] } & \multicolumn{3}{|l|}{ 5-Plex suspension array ${ }^{a}$} & \multirow{2}{*}{$\begin{array}{l}\text { Oral, half-lethal doses for } 10 \mathrm{~kg} \\
\text { child in } 100 \mathrm{~mL}[\mathrm{ng} / \mathrm{L}]^{b}\end{array}$} \\
\hline & & Standard protocol $[\mathrm{ng} / \mathrm{L}]$ & Enrichment protocol [ng/L] & Enrichment factor & \\
\hline Ricin & $2 \pm 1.0$ & $2 \pm 0.4$ & $4 \pm 0.4$ & - & 2000000000 \\
\hline Abrin & $346 \pm 210.5$ & $546 \pm 22.6$ & $85 \pm 6.5$ & 6 & 700000 \\
\hline SEB & $4 \pm 0.1$ & $3 \pm 0.7$ & $0.3 \pm 0.02$ & 10 & $50000^{c}$ \\
\hline BoNT/A & $12 \pm 2.9$ & $21 \pm 0.9$ & $6 \pm 0.7$ & 4 & 80000 \\
\hline BoNT/B & $124 \pm 13.7$ & $73 \pm 5.5$ & $24 \pm 0.08$ & 3 & 80000 \\
\hline
\end{tabular}

a Shown is the comparison of the standard protocol of the 5-plex suspension array using $50 \mathrm{~mL}$ sample volume and microsphere-toxin-incubation for $2 \mathrm{~h}$ versus the enrichment protocol using $500 \mathrm{~mL}$ sample volume and $16 \mathrm{~h}$ incubation time. Data are from one exemplary experiment out of three (Bioplex) or two (ELISA). b The oral half-maximal lethal dose (LD50) of a toxin is the amount that kills $50 \%$ of the animal test population after application per os. For our estimation, we assumed the oral LD50 for a $10 \mathrm{~kg}$ toddler to be present in a $100 \mathrm{~mL}$ serving of food. LD50 data are from refs 56-60. c For SEB, the effective dose (ED50) is used for the calculation.

Table 4 Reactivity of the multiplex toxin assay with different antigensa

\begin{tabular}{|c|c|c|c|c|c|c|}
\hline Antigen & $10^{4} \mathrm{ng} / \mathrm{L}$ & Ricin-beads & Abrin-beads & SEB-beads & BoNT/A-beads & BoNT/B-beads \\
\hline Ricin & 15 & +++ & - & - & - & - \\
\hline R. communis agglutinin & 15 & + & - & - & - & - \\
\hline H. pomatia agglutinin & 15 & - & - & - & - & - \\
\hline D. biflors agglutinin & 15 & - & - & - & - & - \\
\hline Abrin & 15 & - & ++++ & - & - & - \\
\hline SEB & 5 & - & - & ++++ & - & - \\
\hline SEC1 & 5 & - & - & + & - & - \\
\hline $\mathrm{SEC} 2$ & 5 & - & - & - & - & - \\
\hline BoNT/A & 5 & - & - & - & ++++ & - \\
\hline BoNT/A complex & 5 & - & - & - & ++++ & - \\
\hline C. botulinum A strain 2298 & 5 & - & - & - & ++++ & - \\
\hline C. botulinum A strain 2267 & 5 & - & - & - & ++++ & - \\
\hline BoNT/B & 5 & - & - & - & - & ++ \\
\hline BoNT/B complex & 5 & - & - & - & - & ++ \\
\hline C. botulinum B strain 1029 & 5 & - & - & - & - & +++ \\
\hline $\mathrm{BoNT} / \mathrm{E}$ & 5 & - & - & - & - & - \\
\hline BoNT/E complex & 5 & - & - & - & - & - \\
\hline C. botulinum $\mathrm{E}$ strain 2625 & 5 & - & - & - & - & - \\
\hline $\mathrm{BoNT} / \mathrm{F}$ & 5 & - & - & - & - & - \\
\hline BoNT/F complex & 5 & - & - & - & - & - \\
\hline C. botulinum $\mathrm{F}$ strain 2297 & 5 & - & - & - & - & - \\
\hline
\end{tabular}

a The reactivity $\mathrm{R}$ of each bead set in the 5-plex assay was determined according to the formula given in the Experimental section and expressed on a relative scale, where (-) corresponds to $\mathrm{R}<20 \%$; (+) corresponds to R \# 40\%; (++) corresponds to R \# 60\%; (+++) corresponds to R \# $80 \%$ and $(++++)$ corresponds to $\mathrm{R}>80 \%$. 
Table 5 Validation of 5-plex magnetic and fluorescent bead array: concentrations of analytes in standard curves and corresponding within-/betweenassay CVsa

\begin{tabular}{|c|c|c|c|c|c|c|c|c|c|c|}
\hline \multirow[b]{3}{*}{ Conc. } & \multicolumn{10}{|c|}{ Analyte } \\
\hline & \multicolumn{2}{|l|}{ Ricin } & \multicolumn{2}{|l|}{ Abrin } & \multicolumn{2}{|l|}{ SEB } & \multicolumn{2}{|c|}{ BoNT/A } & \multicolumn{2}{|c|}{ BoNT/B } \\
\hline & $\mathrm{ng} / \mathrm{L}$ & $\mathrm{CV}[\%]$ & $\mathrm{ng} / \mathrm{L}$ & $\mathrm{CV}[\%]$ & $\mathrm{ng} / \mathrm{L}$ & $\mathrm{CV}[\%]$ & $\mathrm{ng} / \mathrm{L}$ & $\mathrm{CV}[\%]$ & $\mathrm{ng} / \mathrm{L}$ & $\mathrm{CV}[\%]$ \\
\hline 1 & 10000 & $4 / 23$ & 60000 & $5 / 30$ & 2300 & $1 / 4$ & 2000 & $5 / 16$ & 10000 & $1 / 17$ \\
\hline 2 & 1000 & $11 / 69$ & 6000 & $11 / 25$ & 400 & $11 / 10$ & 200 & $10 / 30$ & 1000 & $5 / 18$ \\
\hline 3 & 100 & $7 / 65$ & 600 & $10 / 14$ & 50 & $17 / 27$ & 20 & $9 / 18$ & 100 & $9 / 20$ \\
\hline Mean & & $7 / 52$ & & $9 / 23$ & & $10 / 14$ & & $7 / 21$ & & $5 / 18$ \\
\hline
\end{tabular}

a The CVs are reported as the within-assay/between-assay CVs for each validation sample above the LOD and the mean CV of at least 6 repetitions are shown. CV calculation: SD/mean $\times 100 \%$.

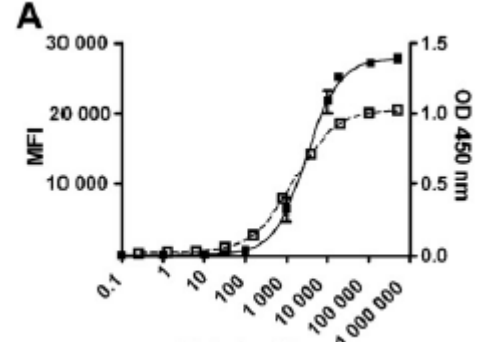

Ricin [ng/L]

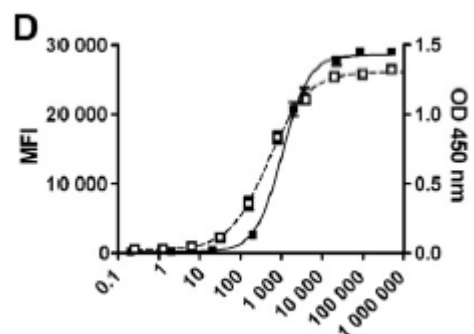

BoNT/A [ng/L]

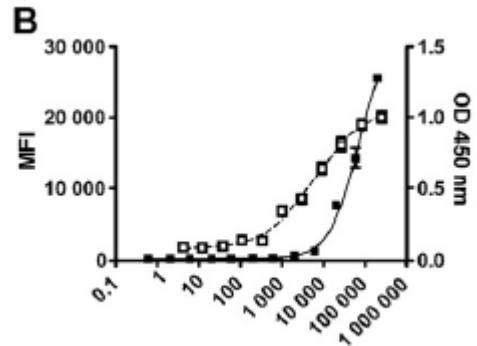

Abrin [ng/L]

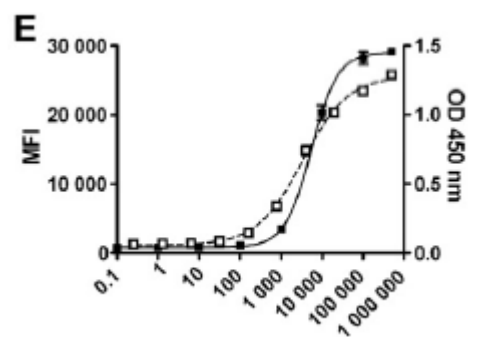

BoNT/B [ng/L]

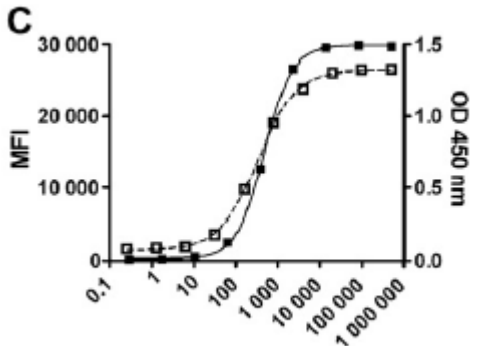

SEB [ng/L]

Fig. 1 Detection of five toxins using a multiplexed magnetic and fluorescent suspension array compared to single-toxin detection via ELISA. In both methods, ricin (A), abrin (B), SEB (C), BoNT/A (D) and BoNT/B (E) were detected using the same capture and detection antibody pairs. The capture antibodies were either immobilised on magnetic and fluorescent microspheres (5-plex suspension array) or on microtiter plates (single-toxin ELISA). Different concentrations of toxins were added and the specific signal was detected either by incubation with a cocktail of biotinylated detection antibodies specific to all five antigens followed by SA-PE (5-plex suspension array) or by incubation with a single, corresponding biotinylated detection antibody and SA-PolyHRP (single-toxin ELISA). Given on the left is the mean fluorescent intensity (MFI) of the reporter signal measured by the Bio-Plex instrument and on the right the optical density at $450 \mathrm{~nm}$. 

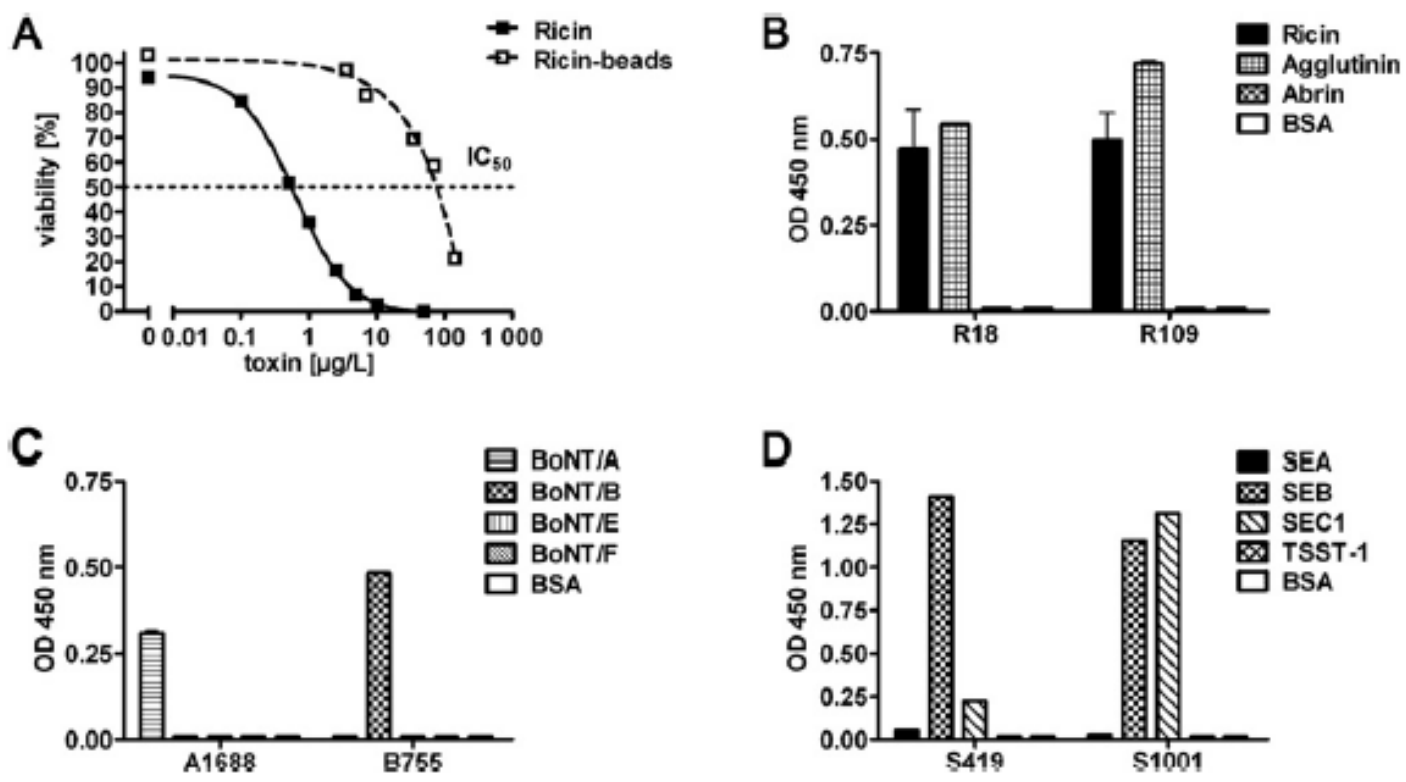

Fig. 2 Generation of toxin-specific antibodies. (A) Immobilised ricin is less toxic than native ricin. Using an in vitro cytotoxicity assay, Vero cells were incubated with different concentrations of native ricin or ricin immobilised on Dynabeads, respectively. The viability of the cells was quantified $24 \mathrm{~h}$ later using a cell proliferation assay as indicated in the Experimental section. (B-D) Specificity of novel mAb used for setting up the fluorescent and magnetic suspension array. (B) Using bead-immobilised ricin as antigen, a number of $m A b$ were obtained (Table 2). mAb R18 and R109 were selected for further studies on the basis of their reactivity in ELISA-based assays. Shown are the results of an indirect ELISA where mAb R18 and R109 were tested against ricin, agglutinin, abrin and BSA ( $500 \mathrm{mg} / \mathrm{L}$ ) immobilised on a microtiter plate. An anti-mouse peroxidase-labelled detection antibody was used for the detection of the specific signal. (C) mAb A1688 and B755 were obtained using a toxoid/toxinimmunisation strategy. The mAb were tested in an indirect ELISA on different BoNT serotypes (/A, /B, /E, /F) or BSA, respectively. (D) mAb S419 and S1001 were obtained after immunising mice with recombinant SEB. The $m A b$ were tested in an indirect ELISA on different staphylococcal enterotoxins (SEA, SEB, SEC1, TSST-1) or BSA, respectively. 

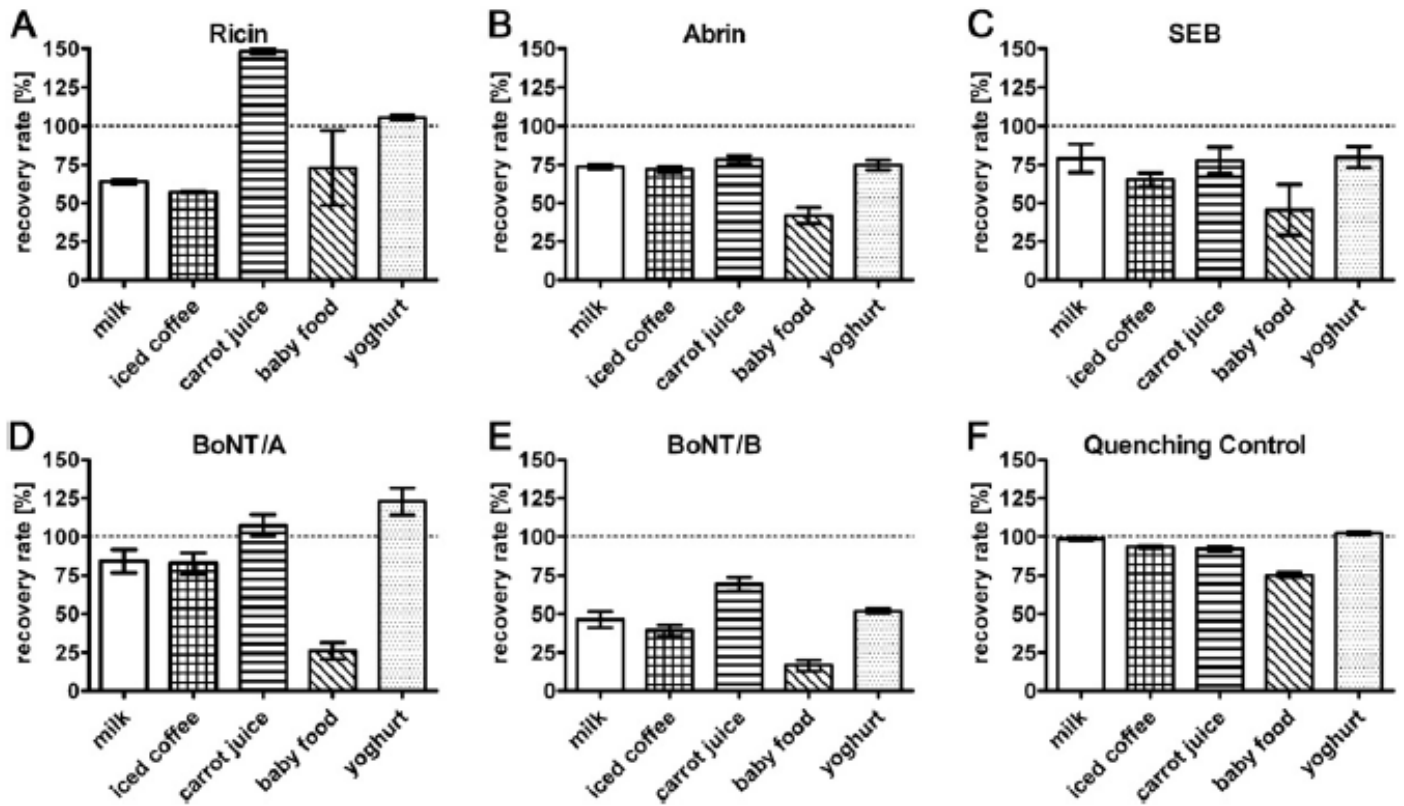

Fig. 3 Multiplex toxin detection from complex food matrices using the 5-plex suspension array. The recovery rates of ricin (A), abrin (B), SEB (C), BoNT/A (D) and BoNT/B (E) from milk, iced coffee, carrot juice, baby food and yoghurt were determined. The food matrices were spiked with EC50 concentrations of the toxin derived from multiplex standard curves (Fig. 1 and Table 1) and the 5-plex suspension array was performed as described in the Experimental section. $(F)$ As a fluorescence quenching control, food matrices or buffer were incubated in a separate reaction with beads covalently coupled to SA-PE. The signal obtained in the complex food matrix was compared to the signal obtained in buffer and expressed as a percentage. 